\title{
A Review of Control Techniques in Photovoltaic Systems
}

\author{
Duberney Murillo-Yarce ${ }^{1} \mathbb{D}$, José Alarcón-Alarcón ${ }^{1} \mathbb{D}$, Marco Rivera ${ }^{2, * \mathbb{C}}$, Carlos Restrepo ${ }^{2} \mathbb{D}$, \\ Javier Muñoz ${ }^{2}$, , Carlos Baier $^{2}(\mathbb{D})$ and Patrick Wheeler ${ }^{3}(D)$ \\ 1 Engineering Systems Doctoral Program, Faculty of Engineering, Universidad de Talca, Curicó 3340000, Chile; \\ duberney.murillo@utalca.cl (D.M.-Y.); jose.alarcon@utalca.cl (J.A.-A.) \\ 2 Faculty of Engineering, Universidad de Talca, Curicó 3340000, Chile; crestrepo@utalca.cl (C.R.); \\ jamunoz@utalca.cl (J.M.); cbaier@utalca.cl (C.B.) \\ 3 Faculty of Engineering, University of Nottingham, Nottingham NG7 2RD, UK; pat.wheeler@nottingham.ac.uk \\ * Correspondence: marcoriv@utalca.cl; Tel.: +56-933-923-996
}

Received: 2 November 2020; Accepted: 15 December 2020; Published: 18 December 2020

\begin{abstract}
Complex control structures are required for the operation of photovoltaic electrical energy systems. In this paper, a general review of the controllers used for photovoltaic systems is presented. This review is based on the most recent papers presented in the literature. The control architectures considered are complex hybrid systems that combine classical and modern techniques, such as artificial intelligence and statistical models. The main contribution of this paper is the synthesis of a generalized control structure and the identification of the latest trends. The main findings are summarized in the development of increasingly robust controllers for operation with improved efficiency, power quality, stability, safety, and economics.
\end{abstract}

Keywords: control techniques; control loops; grid-connected; islanded system; PV system

\section{Introduction}

Solar energy is a renewable energy source. It is an attractive energy solution due to its inexhaustible supply source and it is non-polluting in character. The total amount of incident solar energy on the Earth is much greater than the current and anticipated energy needs of the world. Solar energy has the potential to satisfy all of the future energy needs if it is properly harnessed [1]. During its operation it does not emit greenhouse gas or toxic elements. Its use helps to reduce dependence on fossil fuels, contributing to the reduction of environmental impact [2]. Due to all its advantages, it is expected that in the 21st century solar energy will become the most important renewable source during the energy transition towards a sustainable development. These reasons justify why solar energy is a focus of such research interest.

The control of solar photovoltaic (PV) systems has recently attracted a lot of attention. Over the past few years, many control objectives and controllers have been reported in the literature. Two main objectives can be identified. The first is to obtain the maximum available PV power with maximum power point tracking (MPPT) control and the second objective is the PV power utilisation (application). Power can be obtained from the PV panels and then transformed to supply the load demand or to be injected into the electrical power network [3], as shown in Figure 1. According to the application, PV systems can be classified in two categories: (i) islanded systems, (ii) grid-connected systems. 


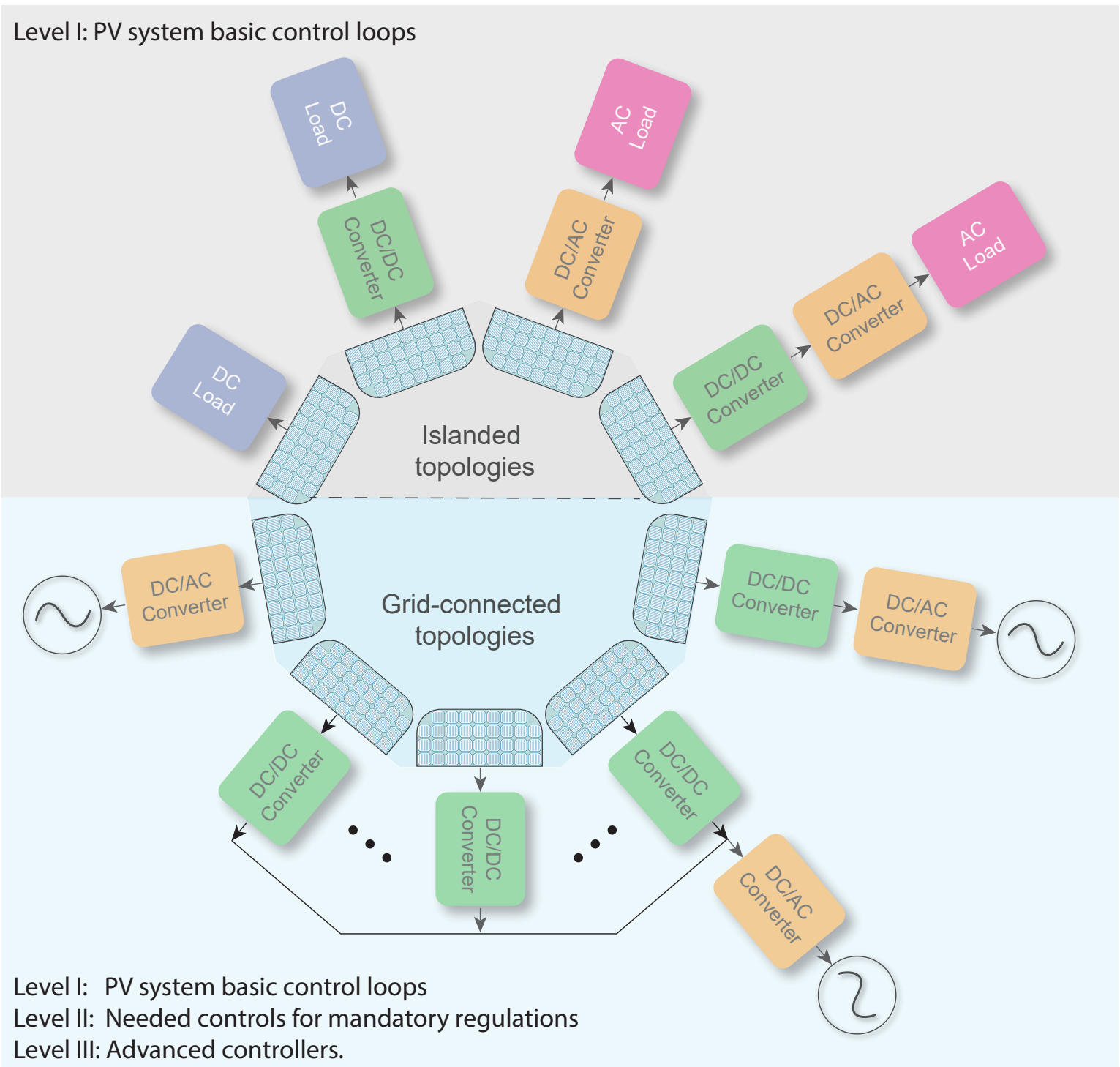

Figure 1. General scheme of photovoltaic (PV) systems topologies and their control levels.

The islanded system concept refers to systems that operate independent of the electrical grid. In islanded systems, ac or dc loads are directly supplied by the PV energy source. Usually the loads are $\mathrm{AC}$, but with the DC power generation from renewable sources the number of DC loads has increased significantly [4]. Examples of potential DC loads are servers, data centers, lighting systems, electric drives for ventilation and air conditioning systems, electric vehicles and desktop computers [5]. In grid-connected systems, the power generated is injected into the electrical network and is used by any load or customer connected to the grid.

The middle blocks in Figure 1 are responsible for the energy conversion. This function is performed by power converters which are electronic circuits based on power switching devices. Power circuits employed in solar energy applications are: (i) DC-DC converters, (ii) DC-AC converters (inverters). Some possible system topologies for islanded and grid-connected systems are shown in Figure 1. Power converters are fundamental components in PV systems because they carry out the control actions. The control requirements of islanded and grid-connected systems are different. Current/voltage controllers and 
MPPTs algorithms are required in both cases. In islanded systems it is possible to implement additional controllers for the energy management of energy storage systems (ESS) and filters to improve the quality of power supplied to loads [6,7].

In grid-connected systems, power inverters transform the DC voltage PV output into AC waveforms for the electrical power grid. The AC waveform must satisfy the amplitude and frequency requirements at the point of common coupling (PCC) [8]. To stablish the connection, phase locked loop (PLL) techniques or synchronization algorithms are required to shynchronize the inverter outputs with the grid voltages [9]. It is also fundamental to control the harmonic content produced by the switching of the inverter's semiconductors that is injected at the PCC [10]. As well as a synchronization algorithm and power quality control, there are additional functions such as anti-islanded protection, energy storage regulation, active power control and grid support required by concepts of quality, continuity and reliability. These functions are mandatory according to grid codes [11]. The objective is that the grid-connected PV systems can enhance the power system dynamics by contributing to fault mitigation and ensuring stability [12]. Furthermore, monitoring, diagnostic and prediction functions are a new trend in a high-power PV systems for economic and optimal operation reasons [13].

The operation of grid-connected PV systems is complex if compared with islanded systems. Consequently, control actions are also complex as higher standards of regulations applied. The control requirements of islanded and grid-connected systems are summarized in Table 1. In general, controllers can be classified into three levels: (i) basic control loops PV systems; (ii) controls needed for mandatory regulations; (iii) advanced controllers. Generalized summary of the controllers used are presented in Table 2. The contribution of this paper is to provide a summary of the most recent control techniques in PV applications. These new trends are presented in a systematic way while the proposed generalized three-level control structure is developed. The proposed methodology allows to address the new publications in the PV systems control topic through an integrated approach, describing the trends of all hierarchical control levels in the same document. This feature differentiates our work from other reviews where only a specific topic is addressed within one of the control levels. The content of this paper is structured as follows. Section 2 introduces the basic controllers. Second-level controllers are presented in Section 3. In Section 4, advanced controllers are discussed. Section 5 presents a discussion of the main findings and it shows how other recent review papers are aligned within the generalized hierarchical structure from three levels. In Section 6 potential challenges in PV systems control are described. Finally, the conclusions of this review are included in Section 7.

Table 1. Control requirements in PV systems.

\begin{tabular}{cl}
\hline \multicolumn{1}{c}{ PV System } & \multicolumn{1}{c}{ Requirements } \\
\hline \multirow{4}{*}{ Islanded } & Current/voltage/power \\
& MPPT \\
& Energy storage \\
& Power quality \\
\hline & Current/voltage/power \\
& MPPT \\
& Synchronization \\
& Anti-islanded protection \\
& Power quality \\
& Active power control \\
& Grid support \\
& Energy storage \\
& Monitoring \\
& Power prediction \\
\hline
\end{tabular}


Table 2. Controllers in PV systems.

\begin{tabular}{|c|c|c|c|}
\hline Level & Control Objective & Strategy & References \\
\hline \multirow{14}{*}{1} & \multirow{7}{*}{ Current/voltage } & PI controllers & [14-16] \\
\hline & & Predictive control & {$[17-20]$} \\
\hline & & Passivity based control & [17] \\
\hline & & Sliding & [19] \\
\hline & & Droop control & [21] \\
\hline & & Adaptive controllers & [22] \\
\hline & & Active disturbance rejection & {$[14]$} \\
\hline & \multirow{2}{*}{ MPPT } & Improved classical & [23-29] \\
\hline & & Intelligent algorithms & [30-36] \\
\hline & \multirow{5}{*}{ Synchronization } & Synchronus frame & {$[37,38]$} \\
\hline & & Generalized integrator & {$[39,40]$} \\
\hline & & PLL in quadrature & [41] \\
\hline & & Enhanced PLL & [42-44] \\
\hline & & Novel synchronization algorithm & [45] \\
\hline \multirow{6}{*}{2} & \multirow{2}{*}{ Power quality } & Active filters & [46-55] \\
\hline & & Hybrid filters & [56] \\
\hline & \multirow{2}{*}{ Anti-islanded protection } & Passive techniques & [57-59] \\
\hline & & Active techniques & [60-64] \\
\hline & \multirow{2}{*}{ Grid support } & Frequency & [65-72] \\
\hline & & Voltage & [73-77] \\
\hline \multirow{11}{*}{3} & \multirow{3}{*}{ Active power limiting } & Direct power control & [78] \\
\hline & & Current limiting & [78] \\
\hline & & Modified MPPTs & {$[79,80]$} \\
\hline & Energy storage & Power control & {$[17,81,82]$} \\
\hline & \multirow{3}{*}{ PV monitoring } & Neural network & [83] \\
\hline & & Genetic algorithms & [84] \\
\hline & & Machine learning & [85] \\
\hline & \multirow{4}{*}{ Power forecasting } & Artificial intelligence & [86-88] \\
\hline & & Statistical methods & {$[89,90]$} \\
\hline & & Physical methods & [91] \\
\hline & & Hybrid algorithms & [91-94] \\
\hline
\end{tabular}

\section{First Level Controllers}

In this Section the basic controllers for PV systems are presented. The first-level controllers are: current and voltage controllers, MPPT methods and synchronization strategies.

\subsection{Current and Voltage Control}

For current and voltage control a two-loop control strategy is usually employed. A condition of this structure is the decoupling of the dynamic response between both loops. The inner loop must be faster than the outer loop. The common structure is to have a inner loop and a voltage outer loop. PI controllers are commonly used in both control loops, but they have disadvantages such as limitations on voltage regulation, conflicts between control loops and small regions of stability [17]. To improve the performance of two-loop strategy, robust non-linear controllers have been proposed. Recent work has addressed several control techniques in two-loop controllers such as: active disturbance rejection [14] and PI controllers [14-16], passivity based control [17], predictive control [17,20], droop control [21] and adaptive controllers [22]. The description of the controllers used in inner and outer loops in this paper is shown in Table 3.

The two-loop control strategy can be replaced by a single control loop or independent control loops. This avoids complicated feedback loops. The control technique with the most potential to replace the inner 
and outer loop with a single loop is predictive control. In [18], a predictive controller is used to regulate the operation of a DC-DC converter and an inverter. An application of independent controllers it is a hybrid approach between predictive and sliding control applied in a grid-connected PV system, where the sliding governs the voltage fluctuations of the DC bus and the predictive control regulates the inverter's performance [19].

Table 3. Controllers employed in two-loop strategy.

\begin{tabular}{|c|c|c|}
\hline Reference & Inner Loop & Outer Loop \\
\hline [14] & PI algorithm for inner current loop & $\begin{array}{l}\text { Active perturbation rejection } \\
\text { in the outer voltage control }\end{array}$ \\
\hline [15] & PI current control & $\begin{array}{l}\text { Outer loop controller is used to voltage } \\
\text { control }\end{array}$ \\
\hline [16] & Inner current and voltage loops & Outer current loop \\
\hline [17] & $\begin{array}{l}\text { Finite control set-model predictive } \\
\text { control as inner current loop }\end{array}$ & $\begin{array}{l}\text { Interconnection damping assessment- } \\
\text { Passivity based controller as outer } \\
\text { controller }\end{array}$ \\
\hline [20] & $\begin{array}{l}\text { Vector oriented control as current } \\
\text { controller }\end{array}$ & $\begin{array}{l}\text { Model predictive control with multiple } \\
\text { steps as voltage and power control }\end{array}$ \\
\hline [21] & Inner loop current droop control & Outer loop voltage droop control \\
\hline [22] & Non-linear current controller & $\begin{array}{l}\text { Adaptive voltage controller with } \\
\text { active disturbance injection }\end{array}$ \\
\hline
\end{tabular}

\subsection{Maximum Power Point Tracking Methods}

In order to obtain the maximum available power from a PV system and to enhance the installation efficiency, MPPT methods are used [23]. The most popular conventional MPPT in full methods are perturb and observe $(\mathrm{P} \& \mathrm{O})$, incremental conductance, fractional open circuit voltage and fractional short circuit current [24]. These algorithms are very popular because of its simplicity and fast convergence [31]. In recent years, MPPT methods based on intelligent techniques such as particle swarm optimization (PSO), genetic algorithms (GA), fuzzy control, simulated annealing algorithm, neural networks and firefly algorithm have been reported [30]. Intelligent algorithms have drawbacks as complex implementation and the difficulty in initial point selection [27]. The current challenge is to introduce robust and reliable MPPT methods. The lines of research addressed in recent publications are focusing on partial shading condition and improved classical techniques [29].

\subsubsection{Improving the Performance of Classical Techniques}

Some drawbacks of classical algorithms are power oscillations in steady state and inefficient tracking under fast changes of irradiance.

- A new control algorithm with a multi-variable $\mathrm{P} \& \mathrm{O}$ is presented in [25]. It is a hybrid multivariable control that combines central and distributed MPPT to extend the MPPT range.

- To eliminate steady state oscillations in P\&O and incremental conductance algorithms, ref. [26] introduces improved system operation.

- The maximum power trapezium (MPT) method is considered as a classic MPPT [27]. In this paper, a modified MPT is proposed. The new algorithm introduces a variable current range lower bound to substitute fixed voltage range upper bound of the traditional MPT method.

\subsubsection{Partial Shading Condition}

PV systems may have multiples peaks under partially shading. MPPT methods can reach a local peak instead of the global peak, decreasing the energy harvesting. 
- $\quad$ Ref. [28] presents a novel maximum point searching design utilizing a maximum power point scanning technique is proposed. This technique is developed into an online or off-line tester and finds out the maximum power point automatically.

- A smart technique is presented in [31] to systematically schedule the search for the global peak, by using the maximum power triangle method.

- Ref. [32] shows a scheme is focusing on the disturbances of random variables by using a flower pollination algorithm.

- An optimization method in a MPPT algorithm is proposed in [33]. The technique named chaotic flower pollination algorithm integrates the chaos maps for an adaptive adjustment of the basic algorithm parameters.

- An improved MPPT control by using a fusion firefly algorithm is presented in [34]. Additionally a novel simplified propagation process is considered.

- A fuzzy logic MPPT optimized by a combination of PSO and GA is presented in [35]. The range of changes in fuzzy membership functions and fuzzy rules are proposed as an optimization problem solved by using PSO-GA.

- Ref. [36] poses an improved gray wolf optimizer. In this nature-inspired algorithm a convergence factor is integrated to improve the dynamic performance.

\subsection{Synchronization}

Synchronization is fundamental in the control of the inverters connected to the grid. It consists of the connection of the generated signals with the same parameters of amplitude, phase and frequency of the power grid. In this process PLL techniques are generally used to perform the synchronization. The operation principle of the PLL is tuning the inverter's voltage with a reference voltage measured at the PCC. According to the technique employed, PLL algorithms can be categorized as: synchronous reference frame, second-order generalized integrator, quadrature PLL and enhanced PLL [41]. Another alternative are synchronization algorithms that do not measure grid voltage. These are based on virtual flow, power instantaneous and observer-based schemes [45].

Generally, classical PLL techniques do not achieve a good phase-angle detection when the voltage grids have large amplitude and phase variations [44]. Robust PLL techniques are required for weak-grid conditions. When there are not ideal conditions at the PCC techniques sensorless are suitable, although hybrid PLL algorithms may result in a good performance. Weak-grid is a challenge widely approached. Additionally, situations like unbalances and grid faults are studied in recent works. The most contributions are algorithms based on PLL [37-40,42,43]. In addition, synchronization techniques without PLL algorithms are presented in [44,45]. A brief description of recent literature is presented below.

- $\quad$ A PLL based on a decoupled double synchronous reference frame is presented in [37]. This structure is suitable for unbalanced grid and variable frequency conditions.

- Ref. [38] proposes a self adaptive controller to operate in both grid connected and islanding condition, with sure transfer between modes without reconfiguring control structure. The controller is designed on the basis of a PLL and two cascaded control loops.

- A SOGI based PLL technique that uses two interdependent loops one for frequency and the other one during the synchronization process is presented in [39].

- Ref. [40] proposes a PLL with second order approximation valid for steady state and transients. Compared with other PLLs, it is more accurate during large phase perturbation by cause of grid faults.

- A PLL based on a dual second order generalized integrator (SOGI) enhanced is presented in [42]. The algorithm realizes a harmonics cancellation before performing sequence calculations. Its application is weak grids. 
- A novel PLL with an improved dual adaptive notch and multivariable filter is presented in [43] for unideal grid conditions.

- $\quad$ Ref. [44] proposes an extra function on the basis of direct phase-angle detection method to support asymmetrical grids.

- A novel grid synchronization technique with bumpless start is proposed in [45]. The method reduces the computational effort and can operate in an unbalanced and distorted weak grid.

\section{Second Level Controllers}

In this section the controllers which satisfy mandatory regulations for the operation of PV systems connected to grid are detailed. Control strategies that improve power quality, perform anti-islanding protection and grid support are also presented.

\subsection{Power Quality}

To achieve power quality according to specifications, control structures for inverters in PV systems must adopt harmonic compensation algorithms. IEEE Std 519 recommends a harmonic distortion of less than $5 \%$. Harmonics are due to non-linear behaviour of elements connected to the power grid that produce undesired phenomena in both grid and connected loads. In order to attenuate these effects, control actions are implemented reducing the currents harmonics injected to the grid. The simplest strategy is to use passive filters designed for the frequencies to be eliminated. A more suitable strategy is to use active filters which inject compensation currents to cancel the effect of the harmonics [46,55]. There are also filters that combine active and passive technologies known as hybrid filters [56]. There are two strategies for active compensation: methods based on harmonics detection in the load and selective harmonic compensation. In order to detect the harmonic content at the PCC, harmonic compensation strategies such as instantaneous power, conservative power theory and SOGI are used $[48,49,52,56]$. The second strategy is selective harmonic compensation, in which the controllers are tuned at the harmonic to be eliminated [50,51]. Discrete Fourier Transform (DFT) method is usually applied to detect the harmonic content to compensate. Additionally, first harmonics can be detected considering a compensation strategy and a low pass filter (LPF) $[53,54]$. Additional information about these contributions is given below.

\subsubsection{Harmonic Detection in the Load}

- In [46] harmonic components are obtained in synchronous rotating DQ frame, as a subtraction between instantaneous current and fundamental components.

- Instantaneous power theory is applied utilizing LPFs to detect the compensation currents $[47,56]$. Harmonics compensation is an ancillary service in a PV system under variable radiation [47] or a hysteresis band controller in the control loop [56].

- The unbalanced output power problem in single-phase cascaded H-bridge PV inverter is studied in $[48,49]$. This condition results in a higher harmonic content of the grid current. In [48], a novel harmonic compensation technique is proposed. In this strategy, harmonic components are obtained from DC-link average voltage calculated by means of a notch filter. In [49], multiples harmonics are injected in overmodulation and non-overmodulation regions, to extend the linear modulation range and compensate grid current harmonics.

\subsubsection{Selective Harmonic Compensation}

- Methods based on the traditional DFT are used to detect the load current harmonic content [50,51]. A sliding DFT is applied in a dynamic current saturation algorithm. Sliding DFT provides high computational efficiency in comparison with traditional algorithm [50]. An enhanced DFT is 
proposed. The controller provides a feedback for each harmonic being able to compensate different harmonics [51].

- A flexible method of selective compensation based on instantaneous power theory is presented in [52]. Compensation current is calculated according to THD index and power factor, injecting to grid active component or reactive component or both.

- A new technique to compensate second order harmonic component is proposed in [53]. This technique is based on cascaded LPFs and synchronous rotating DQ frame.

- Ref. [54] considers the current saturation problem and the compensation of the extra harmonics generated in this process. Two saturation techniques are proposed. Harmonic current components are detected applying SOGI based method.

\subsection{Anti-Islanding Protection}

Anti-islanding protection is a required function of grid-connected systems. The objective is to disconnect the solar modules during power outages of the grid. Disconnection isolates potential problems to avoid damage to PV components [58] and promotes safe conditions for performing maintenance [63]. The proposed techniques are classified as active or passive. In active techniques, a perturbation is applied to grid while in passive techniques, electrical variables are analyzed at the PCC. The most recent active and pasive techniques of anti-islanding detection methods are:

\subsubsection{Active Techniques}

- A method based on reactive power perturbation is presented in [60]. This islanding detection method poses a reactive power $\mathrm{P} \& \mathrm{O}$ anti-islanding method for indirect current control. The proposed algorithm introduces a small reactive power disturbance in the inverter output and detects the islanding by observing reactive power mismatch during the islanding condition.

- An approach based on the periodical injection of a second order harmonic current component and evaluates grid response through a new cross-correlation anti-islanding detection is proposed in [61]. This approach is focused in module integrated converters with pseudo dc-link.

- Ref. [62] proposes a hybrid method for islanding detection. The proposed scheme injects a low frequency sinusoidal perturbation signal into the d-axis current control loop.

- A comparative analysis of active anti-islanding techniques based on the frequency drift is presented in [63]. These techniques are the classic active frequency drift (AFD), AFD with pulsating chopping factor and AFD with positive feedback.

- An hybrid islanding detection strategy that exploits Gibbs phenomenon on the interpolation of two voltage sinusoidal functions is described in [64]. The proposed technique combines active and passive methods of frequency rate of change at a given moment while the voltage THD is monitored.

\subsubsection{Passive Techniques}

- A detection scheme based on support vector machine is presented in [57]. This method exploits powerful classification capability. Algorithm collects measures of current, voltage, power, frequency and THD.

- $\quad$ Ref. [58] proposes a scheme based on the detection of voltages and frequencies higher and lower than the admissible values. This method reduces the non-detection zone of passive islanding techniques.

- A passive method with an adaptive algorithm is presented in [59]. This paper proposes a new islanding detection strategy based on the combination of an adaptive neuro-fuzzy inference system (ANFIS) approach and passive monitoring techniques of system variables. The method exploits the pattern recognition of ANFIS approach to detect the islanding condition. 


\subsection{Grid Support}

Practical experience indicates that with a large penetration of PV generation in a power grid more challenges and problems appear $[72,95,96]$. Therefore, it is necessary to implement grid support functions in the control loops. Grid-connected PV systems must satisfy several requirements to contribute to normalize the grid operating under perturbations. The minimal requirements are voltage, frequency and reactive power conditions. These regulations are imposed by grid codes to maintain stability and reliability of the power grid. In line with grid codes, PV systems have to be able to stay connected and have fault ride-through capabilities. Different robust control schemes for frequency and voltage have been proposed to deal with the dynamics issues of the grid [97]. The effect in the grid is the flexible injection of active and reactive power according to the grid conditions [98].

\subsubsection{Frequency Support}

Nowadays, it is still found that some classes of PV converters and their controls can generate transient events completely opposite to the responses of a grid with inertia, which contributes a destabilizing effect on the power grids [65]. This is one of the reasons why PV systems can provide virtual inertia (through their control strategies) to the grid [66-69]. Although most of the virtual inertia strategies need energy storage [66], it is possible to use the energy reserve in the PV systems to generate the desired response, without the need for storage [70]. It is important to recognize that the strategies that provide virtual inertia (or virtual synchronous generation) are not the only scheme that can contribute to frequency support. In general, if the PV system has battery storage or even hybrid storage, a system with droop control may be sufficient to support the frequency [71,72].

\subsubsection{Voltage Support}

Solar plants inject generally reactive power components for voltage support. In [73], reactive power is injected to support line-to-ground and three line-to-ground faults. In [74], the effect of injecting negative sequence reactive current into the grid in case of asymmetrical faults is investigated. To support the grid, negative sequence reactive current is injected suppressing the negative sequence voltage. However, active and reactive currents can be injected simultaneously to support the grid. In [75,77], the asymmetrical faults problem is approached. The proposed strategy in [75] employs dual vector current control to ensure optimal current injection and low voltage ride through. In [77], a new voltage-support technique by using a negative sequence voltage at PCC is presented. This strategy helps to improve the short-term voltage stability and regulate the phase voltages within the margins.

\section{Third Level Controllers}

This section discusses additional control objectives that optimize the operation of PV systems. Third level controllers contribute to fault mitigation and stability.

\subsection{Active Power Limiting}

Limitating active power helps to overcome the frequency and voltage fluctuations as a result of the large penetration of the PV. According to operation point, the control algorithms limits the maximum power that PV system can inject into grid. The techniques used are direct power control, current limiting and modified MPPT methods [78]. In direct power control and current limiting methods, PV systems must be provided with reserve capability. ESS contribute to flexible operation to store or release power energy.

Direct power control method is based on power settings, in which the limit power is tracked by power controllers. Similarly, a PV generation regulation can be implemented through a current control 
loop with a current reference proportional to limit power. This method is known as current limiting. Direct power control and current limiting methods operate independently of the MPPT methods. But, modified MPPT methods can also limit active power. Nodaways, this alternative is a major focus of attention. These control schemes can operate at MPPT or constant power generation mode. For instance, an adaptation of the $\mathrm{P} \& \mathrm{O}$ method is presented in order to track a reference of active power [79]. The same MPPT algorithm is modified in [80] for power regulation, moving the operation point to the left side of MPP with a consideration of stability.

For optimal performance of ESS, energy management strategies must be included.

\subsection{Energy Storage Systems}

Additional energy can be stored during the day and used at night to supply critical loads or for grid support. Stored energy is important in the flexible control of power flow, because used appropriately it reduces losses, power in distribution lines, reverse energy flow and supports voltage and reactive power [82]. In recent publications can be identified two principal objectives about ESS. The first one consists of the optimal sizing. This purpose is approached in [81], where optimal designs using real-world data are discussed. Additionally scheduling of charge/discharge is minimized. Optimal control of charge/discharge of ESS is the second objective. In general, restrictions must be implemented in the control laws to limit the charge/discharge of ESS and to increase its life span. It should consider that the investment cost of ESS is high and it is a priority to extend the operating time. Usually, PI controllers have been used to charge/discharge control of ESS. But a cause of their disadvantages, nonlinear controllers have been proposed.

\subsection{Photovoltaic Monitoring}

To achieve better performance from PV systems and increase equipment life time, the use of monitoring and control software has become popular. Software tools are responsible for acquisition, visualization and data storage [99]. This software can include smart functions to diagnose and estimate degradation of solar panels. Data processing techniques and intelligent algorithms are used in the diagnostic process.

Data processing techniques commonly used in PV systems monitoring include neural networks and machine learning. For example, a novel real-time monitoring tool considering a neural network is presented in [83]. The algorithm predicts the power generation of a PV panel in normal operation under changing environmental conditions. These results allow to identify if the solar panel exhibits degradation by cause of fault conditions. In [85], a method of monitoring solar panels for the identification of degradation based on machine learning techniques is presented. The development of the model and its validation are based on panel and weather data.

In previous cases data was obtained from the normal operation of the solar panel. Also, active procedures that perturb the system can provide data for the PV diagnostic tool, an example is presented in [84]. The proposed system consists of data acquisition and control units. For testing the solar panels, it is injected large-signal perturbations into their panel voltages. After that, voltage and current are sampled, thus it is obtained the current-voltage characteristics of the solar panel. Then, a genetic algorithm extracts the parameters of the curve. Finally, panel degradation is observed according to the parameter's variation.

\subsection{Power Forecasting}

PV power generation is highly dependent on weather conditions [92]. Then, prediction techniques are essential to reduce the unbalance between expected power and real power generation, and support power system operation $[86,89]$. Forecasting models can be classified in two categories: indirect and direct 
models. In indirect forecasting models a weather prediction is the input of PV simulation softwares, which provide the power prediction. Meanwhile, direct models use directly historical data of weather and PV power generation to get the prediction [92].

The most common predictions methods for PV generation are artificial intelligence based models $[87,88]$. Several artificial intelligence techniques are artificial neural network (ANN), support vector machine (SVM), machine learning (ML) and regressive methods. Additional categories are statistical [90], physical models [91] and hybrid models [91,93,94].

- Two artificial intelligence techniques are proposed in [87]: auto-regressive integrated moving average model with an ANN model considering weighing factors computed periodically by means of least squares method.

- $\quad$ Ref. [88] analyzes the performance of different machine learning models that predict the PV power generation. The forecasting models are developed by using historic data of PV power and weather predictions.

- A model uses historic PV generation and weather data is presented in [90]. A Bayesian network performs data inference. The approach also incorporates spatial similarity and temporal correlation to support the power prediction.

- A novel solar generation forecasting proposal based on exploring weather factors from PV model is presented in [91]. The method is performed at three stages: PV systems modeling, machine learning methods for mapping weather features with solar power and forecast adjustment.

- In [92] PV generation estimation is achieved by using numerical weather prediction (NWP). Historical data is processing in NWP products.

- A PV output forecast based on weather prediction is presented in [93]. K-means clustering algorithm is employed to classify historical generation data and the correlation analysis method reduces the dimension of the inputs. Prediction model is solved by considering the long-short memory neural network combined with attention mechanism.

- In [94] a forecasting method based on the ANFIS approach is presented to optimize peak load reduction. The forecasted results are used to calculate the BESS capacity and a FLC considering BESS capacity and PV power determines optimal BESS usage for the sake of power peak curtailment.

An improved PV generation prediction can be obtained incorporating a forecast adjustment stage. Thus, an additional term is included to improve the results. This function is implemented in [89,91]. In [91], the errors are reduced with a term result of a deviation analysis by using the cross-validation for historical data. In [89], a method for adjusting the solar radiation forecast from a numerical weather prediction model is presented, based on the tendency of past error occurrence.

\section{Discussion}

Initially the main findings identified in this study are exposed. After other review papers which have been recently published are presented establishing how their contributions are aligned within the generalized hierarchical structure from three levels.

\subsection{Identified Findings}

The development and implementation of control laws for stable operation of PV systems has been possible thanks to the integration of different disciplines such as control theory, power electronics, electrical power systems, communications, embedded hardware, software and data processing.

DC-DC and DC-AC power converters are fundamental blocks in the conversion and control of PV systems. DC-DC converters transform the power generation by solar panels to different values of direct current. Generally, boost converter are used to increase DC voltage level at the solar panel output and 
provide high voltages to the next stage of energy conversion. DC-DC converters are often responsible for monitoring maximum power and regulating DC buses. On the other hand, power inverters transform the DC into AC signals according to the parameters of the grid. Classic topologies such as two-level inverters is used in low power applications. For higher power several topologies of multilevel inverters are proposed. The most popular are flying capacitor, neutral-point-clamped inverters, T-type structures, cascaded H-bridge, and Packed U-Cell converter [46].

In PV systems controller design, there are two fundamental features to consider, category and architecture. The possible categories in PV systems are islanded and Grid-connected systems. The architecture is based in the power conversion process, where participate DC-DC and DC-AC converters. The architectures are classified according to the number of conversion stages as one stage, two stages or multi-stages. Category and architecture criteria define the control structure of the PV systems. Islanded systems are less demanding regarding control requirements and mandatory regulations. Grid-connected systems must satisfy demanding standards requiring more complex controllers. The main control objectives in PV systems are maximum power and power quality. But, considering the growth of PV systems and other renewable energies connected to power grid, current grid codes are adapting new impositions to mandate that distributed energy resources have specific grid support functions. This is why power inverters must be incorporate control solutions to operate while managing anti-islanded protections, voltage/frequency ride-through, and active/reactive power control during perturbations [73]. In order to satisfy grid codes regulations, control package must be include controls of voltage, frequency, active power, reactive power reference and power factor $[79,98]$. The next generation of inverters are the smart inverters with multiple functions, which are being designed according to the new requirements. Grid support functions are essential to ensure the service reliability and to maintain the grid stability. Then, PV systems are not only power generation systems but also active systems to optimize the grid performance.

In general, control structures are hybrid systems that combine linear and non-linear techniques; as well as classical techniques, advanced control and artificial intelligence methods. In PV systems are integrated classic techniques of control theory, electrical power systems and power converters. The control structures that satisfy standards and grid codes allow to improve safety, quality, efficiency and stability in power system. To operate the power system optimally and to increase the reliability, additional functions of monitoring, diagnostic and prediction are required.

\subsection{Other Review Papers}

The objective of this subsection is to present other recently published review papers that provide by themselves detailed analyzes of specific topics within the generalized hierarchical structure that was presented in the previous sections. Each article focuses on a particular study objective, generally addressing topics at a single hierarchical level. The reviews associated with the first level were presented in [100-103], while in [102-105] the reviews of the controllers located at the second level are addressed and the reviews that study control topics at the third level are developed in [106-110]. In special cases the study objective has been approached at two levels. In [102,103] control topics located at first and second levels were addressed, the study topics were grid-connected systems and PV grid-connected inverters. The review papers and their performance levels are summarized in Table 4. 
Table 4. Abborded control topics by recent reviews.

\begin{tabular}{cll}
\hline Level & Control Objective & References \\
\hline \multirow{2}{*}{1} & MPPT & {$[100-102]$} \\
& Synchronization & {$[102,103]$} \\
\hline \multirow{2}{*}{2} & Power quality & {$[105]$} \\
& Anti-islanded protection & {$[102]$} \\
& Grid support & {$[103,104]$} \\
\hline \multirow{2}{*}{3} & Energy storage & {$[107]$} \\
& PV monitoring & {$[108]$} \\
& Power forecasting & {$[106,109,110]$} \\
\hline
\end{tabular}

\section{Potential Challenges}

According to the classification of control techniques proposed in this paper, the identified research challenges are mainly associated with second and third levels of the generalized control structure. It is a fact that the basic techniques of the first level control have been widely addressed in the literature. In addition in a complex PV control system, the first level controllers finally follow references imposed by higher level controllers. Second and third level controllers are responsible for system's optimal operation which can be seen as a concept that takes into consideration technical, economic, regulation and safety criteria.

Second level controllers are aligned with grid code requirements and international standards which will continue being a reference for designing increasingly robust controllers and for developing the necessary hardware for implementation purpose of these control techniques. In this way, the trend is to change the classic concept of inverters for that of intelligent multi-function inverters. At the third level several challenges have been established, the most important is to narrow the gap between the generation prediction and the generated power. In addition, a scenario that nowadays receives more and more attention is the development of specific software solutions for PV systems that fulfill among other functions with monitoring, diagnostic, prediction and controlling. It is very important to mention that due to the great energy harvesting areas of PV solar farms the communication networks and its security are very critical. In fact, communications play an important role in complex control loops, the use of software tools, access to databases, real-time processing and online resources, among other important PV systems requirements.

Overall the challenges in the control techniques of PV systems can be framed along with the following research areas:

- Control techniques with a trade-off between simplicity and effectiveness.

- Optimal integration of controllers.

- Control algorithms with the potential to perform functions in more than one control level (multi-function and multilevel controllers).

- Specialized software of reasonable cost with self-learning ability.

- Secure and reliable communications.

- Processing of high data volumes.

- Hardware with greater computing power and fast time response.

- Adaptive and smart protection systems.

- Control and communication architectures.

- Longer component life spans and lower costs.

- Optimal energy management.

\section{Conclusions}

This paper has presented a review of the most recent control techniques used in PV solar systems. Many control objectives and controllers have been reported in the literature. In this work, two control 
objectives were established. The first objective is to obtain the maximum available power and the second one, is related with energy conversion and its end-use. The control techniques were presented in a systematic way while a generalized three-level control structure was developed. This methodology allows to address the new contributions of all hierarchical control levels in the same document unlike other review papers where only a specific topic is addressed within one of the control levels. The first level is the basic control loops, at the intermediate level the necessary controls to comply with mandatory regulations and at the third level are the advanced controllers. On the first level voltage and current control, MPPT methods, and synchronization techniques are discussed. On the second level power quality, anti-islanding protection and grid support are widely explained. Finally, in the third level active power limitation, energy storage, monitoring and prediction of PV power generation are analyzed.

The large amounts of PV power bring new challenges for operation and planning of power systems. The general trend identified in PV systems control is the development of increasingly robust controllers for operation under better conditions of efficiency, quality, stability, safety and economic operation. In addition, forecasting methods are essential to reduce expected/real power generation unbalance, to support power system operation.

Author Contributions: D.M.-Y., J.A.-A., M.R., C.R., J.M., C.B., P.W. have contributed equally to the work. All authors have read and agreed to the published version of the manuscript.

Funding: This work was supported by the Chilean Government under Project CONICYT/FONDECYT/ 1191028, CONICYT/FONDECYT/1191680, CONICYT/FONDECYT/MEC80180097, CONICYT/FONDECYT/ MEC80190074 and CONICYTPFECHA/Doctorado-Nacional/2019-21191663. The work was also supported by SERC Chile (CONICYT/FONDAP/15110019).

Conflicts of Interest: The authors declare no conflict of interest.

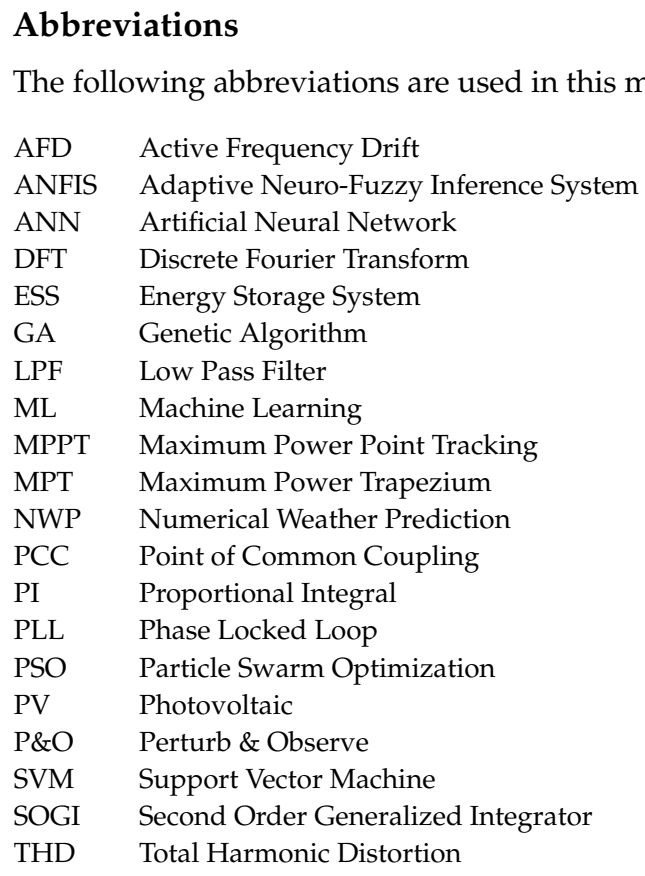




\section{References}

1. Ullah, S.; Branquinho, R.; Mateus, T.; Martins, R.; Fortunato, E.; Rasheed, T.; Sher, F. Solution Combustion Synthesis of Transparent Conducting Thin Films for Sustainable Photovoltaic Applications. Sustainability 2020, 12, 10423. [CrossRef]

2. Almutairi, A.; Abo-Khalil, A.; Sayed, K.; Albagami, N. MPPT for a PV Grid-Connected System to Improve Efficiency under Partial Shading Conditions. Sustainability 2020, 12, 10310. [CrossRef]

3. Ammar, R.B.; Ammar, M.B.; Oualha, A. Fuzzy Intelligent Management of Inter-Exchanged Energy between Standalone Photovoltaic Systems. In Proceedings of the 2019 19th International Conference on Sciences and Techniques of Automatic Control and Computer Engineering (STA), Sousse, Tunisia, 24-26 March 2019; pp. 292-297.

4. Schrittwieser, L.; Leibl, M.; Kolar, J.W. 99\% Efficient Isolated Three-Phase Matrix-Type DAB Buck-Boost PFC Rectifier. IEEE Trans. Power Electron. 2019, 35, 138-157. [CrossRef]

5. Wang, H.; Wu, W.; Li, Y.; Blaabjerg, F. A Coupled-Inductor-Based Buck-Boost AC-DC Converter with Balanced DC Output Voltages. IEEE Trans. Power Electron. 2019, 34, 151-159. [CrossRef]

6. Bukar, A.L.; Tan, C.W. A Review on Stand-Alone Photovoltaic-Wind Energy System with Fuel Cell: System Optimization and Energy Management Strategy. J. Clean. Prod. 2019, 221, 73-88. [CrossRef]

7. Ashtiani, M.N.; Toopshekan, A.; Yousefi, H.; Maleki, A. Techno-Economic Analysis of a Grid-Connected PV/Battery System Using the Teaching-Learning-Based Optimization Algorithm. Sol. Energy 2020, $203,69-82$. [CrossRef]

8. Al-Shetwi, A.Q.; Hannan, M.; Jern, K.P.; Mansur, M.; Mahlia, T. Grid-Connected Renewable Energy Sources: Review of the Recent Integration Requirements and Control Methods. J. Clean. Prod. 2020, 253, 119831. [CrossRef]

9. Ali, Z.; Christofides, N.; Saleem, K.; Polycarpou, A.; Mehran, K. Performance Evaluation and Benchmarking of PLL Algorithms for Grid-Connected RES Applications. IET Renew. Power Gener. 2019, 14, 52-62. [CrossRef]

10. Elkholy, A. Harmonics Assessment and Mathematical Modeling of Power Quality Parameters for Low Voltage Grid Connected Photovoltaic Systems. Sol. Energy 2019, 183, 315-326. [CrossRef]

11. Sarkar, M.N.I.; Meegahapola, L.G.; Datta, M. Reactive Power Management in Renewable Rich Power Grids: A Review of Grid-Codes, Renewable Generators, Support Devices, Control Strategies and Optimization Algorithms. IEEE Access 2018, 6, 41458-41489. [CrossRef]

12. Azghandi, M.A.; Barakati, S.M. A Temporary Overvoltages Mitigation Strategy for Grid-Connected Photovoltaic Systems Based on Current-Source Inverters. Iran. J. Sci. Technol. Trans. Electr. Eng. 2020, 44, 1253-1262. [CrossRef]

13. Livera, A.; Theristis, M.; Makrides, G.; Georghiou, G.E. Recent Advances in Failure Diagnosis Techniques Based on Performance Data Analysis for Grid-Connected Photovoltaic Systems. Renew. Energy 2019, 133, $126-143$. [CrossRef]

14. Chuang, M.; Hong, L. Research on Photovoltaic Grid-connected Control of Z Source Inverter Based on Active Disturbance Rejection Technology. In Proceedings of the 2019 IEEE 4th Advanced Information Technology, Electronic and Automation Control Conference (IAEAC), Chengdu, China, 20-22 December 2019; Volume 1, pp. 2648-2652.

15. Bhagiya, R.D.; Patel, D.R.M. PWM based Double loop PI Control of a Bidirectional DC-DC Converter in a Standalone PV / Battery DC Power System. In Proceedings of the 2019 IEEE 16th India Council International Conference (INDICON), Rajkot, India, 13-15 December 2019; pp. 1-4.

16. Yadav, A.; Chandra, S. Single stage high boost Quasi-Z-Source inverter for off-grid photovoltaic application. In Proceedings of the 2020 International Conference on Power Electronics IoT Applications in Renewable Energy and its Control (PARC), Mathura, India, 28-29 February 2020; pp. 257-262.

17. Ravada, B.R.; Tummuru, N.R. Control of a Supercapacitor/Battery/PV based Stand-Alone DC-Microgrid.IEEE Trans. Energy Convers. 2020, 35, 1268-1277. [CrossRef]

18. Shan, Y.; Hu, J.; Guerrero, J.M. A Model Predictive Power Control Method for PV and Energy Storage Systems with Voltage Support Capability. IEEE Trans. Smart Grid 2020, 11, 1018-1029. [CrossRef] 
19. Rahman Habib, H.U.; Wang, S.; Elmorshedy, M.F.; Waqar, A.; Imran, R.M.; Kotb, K.M. Performance Enhancement of Power Converters for PV-Based Microgrid using Model Predictive Control. In Proceedings of the 2019 International Conference on Electrical, Communication, and Computer Engineering (ICECCE), Kuala Lumpur, Malaysia, 24-25 July 2019; pp. 1-6.

20. Arteaga, M.U.; Ruiz, A.G.; Rivera, M. Control of Energy Storage and Photovoltaic Systems using Model Predictive Control. In Proceedings of the 2019 International Conference on Smart Energy Systems and Technologies (SEST), Porto, Portuga, 9-11 September 2019; pp. 1-6.

21. Nasir, M.; Khan, H.A.; Niazi, K.A.K.; Jin, Z.; Guerrero, J.M. Dual-loop control strategy applied to PV/battery-based islanded DC microgrids for swarm electrification of developing regions. J. Eng. 2019, 2019, 5298-5302. [CrossRef]

22. Bellinaso, L.V.; Figueira, H.H.; Basquera, M.F.; Vieira, R.P.; Gründling, H.A.; Michels, L. Cascade Control with Adaptive Voltage Controller Applied to Photovoltaic Boost Converters. IEEE Trans. Ind. Appl. 2019, 55, $1903-1912$. [CrossRef]

23. Zurbriggen, I.G.; Ordonez, M. PV Energy Harvesting Under Extremely Fast Changing Irradiance: State-Plane Direct MPPT. IEEE Trans. Ind. Electron. 2019, 66, 1852-1861. [CrossRef]

24. Triki, Y.; Bechouche, A.; Seddiki, H.; Abdeslam, D.O. ADALINE Based MPPT with Indirect Control Mode for Photovoltaic Systems. In Proceedings of the 2019 IEEE 28th International Symposium on Industrial Electronics (ISIE), Vancouver, BC, Canada, 12-14 June 2019; pp. 2183-2188.

25. Erauskin, R.L.; Gonzalez, A.; Petrone, G.; Spagnuolo, G.; Gyselinck, J. Multi-Variable Perturb \& Observe Algorithm for Grid-tied PV Systems with Joint Central and Distributed MPPT Configuration. IEEE Trans. Sustain. Energy 2020, 12, 360-367.

26. Bhattacharyya, S.; Patnam, D.S.K.; Samanta, S.; Mishra, S. Steady Output and Fast Tracking MPPT (SOFT MPPT) for P\&O and InC Algorithms. IEEE Trans. Sustain. Energy 2020, 12, 293-302.

27. Xu, S.; Gao, Y.; Zhou, G.; Mao, G. A Global Maximum Power Point Tracking Algorithm for Photovoltaic Systems Under Partially Shaded Conditions Using Modified Maximum Power Trapezium Method. IEEE Trans. Ind. Electron. 2020, 68, 370-380. [CrossRef]

28. Lin, B.; Wang, L.; Wu, Q.H. Maximum Power Point Scanning for PV Systems Under Various Partial Shading Conditions. IEEE Trans. Sustain. Energy 2020, 11, 2556-2566. [CrossRef]

29. Mendez, E.; Ortiz, A.; Ponce, P.; Macias, I.; Balderas, D.; Molina, A. Improved MPPT Algorithm for Photovoltaic Systems Based on the Earthquake Optimization Algorithm. Energies 2020, 13, 3047. [CrossRef]

30. Zhang, W.; Zhou, G.; Ni, H.; Sun, Y. A Modified Hybrid Maximum Power Point Tracking Method for Photovoltaic Arrays Under Partially Shading Condition. IEEE Access 2019, 7, 160091-160100. [CrossRef]

31. Kermadi, M.; Salam, Z.; Ahmed, J.; Berkouk, E.M. A High-Performance Global Maximum Power Point Tracker of PV System for Rapidly Changing Partial Shading Condition. IEEE Trans. Ind. Electron. 2020, 68, $2236-2245$. [CrossRef]

32. Elbehairy, N.M.; Swief, R.A.; Abdin, A.M.; Abdelsalam, T.S. Maximum Power Point Tracking For a Stand Alone PV System Under Shading Conditions Using Flower Pollination Algorithm. In Proceedings of the 2019 21st International Middle East Power Systems Conference (MEPCON), Cairo, Egypt, 17-19 December 2019; pp. 840-845.

33. Yousri, D.; Babu, T.S.; Allam, D.; Ramachandaramurthy, V.K.; Etiba, M.B. A Novel Chaotic Flower Pollination Algorithm for Global Maximum Power Point Tracking for Photovoltaic System Under Partial Shading Conditions. IEEE Access 2019, 7, 121432-121445. [CrossRef]

34. Huang, Y.; Huang, M.; Ye, C. A Fusion Firefly Algorithm with Simplified Propagation for Photovoltaic MPPT under Partial Shading Conditions. IEEE Trans. Sustain. Energy 2020, 11, 2641-2652. [CrossRef]

35. Dehghani, M.; Taghipour, M.; Gharehpetian, G.B.; Abedi, M. Optimized Fuzzy Controller for MPPT of Grid-Connected PV Systems in Rapidly Changing Atmospheric Conditions. J. Mod. Power Syst. Clean Energy 2020, 1-8. [CrossRef]

36. Guo, K.; Cui, L.; Mao, M.; Zhou, L.; Zhang, Q. An Improved Gray Wolf Optimizer MPPT Algorithm for PV system with BFBIC Converter under Partial Shading. IEEE Access 2020, 8, 103476-103490. [CrossRef] 
37. Kalaivani, C.; Rajambal, K. Grid Integration of Three-phase Inverter using Decoupled Double Synchronus Reference Frame PLL. In Proceedings of the 2019 International Conference on Computation of Power, Energy, Information and Communication (ICCPEIC), Melmaruvathur, Chennai, India, 27-28 March 2019; pp. 221-226.

38. Meng, X.; Liu, X.; He, M.; Liu, Z.; Liu, J. A Self-Adaptive Controller for Inverter with Seamless Transfer and Automatic Presynchronization Capability. IEEE Access 2020, 8, 105936-105949. [CrossRef]

39. Sahoo, A.; Mahmud, K.; Ciobotaru, M.; Ravishankar, J. Adaptive Grid Synchronization Technique for Single-phase Inverters in AC Microgrid. In Proceedings of the 2019 IEEE Energy Conversion Congress and Exposition (ECCE), Baltimore, MD, USA, 29 September-3 October 2019; pp. 4441-4446.

40. Zou, Z.; Rosso, R.; Liserre, M. Modeling of the Phase Detector of a Synchronous-Reference-Frame Phase-Locked Loop based on Second-Order Approximation. IEEE J. Emerg. Sel. Top. Power Electron. 2019, 8, 2534-2545. [CrossRef]

41. de Carvalho, M.M.; Medeiros, R.L.P.; Bessa, I.V.; Junior, F.A.C.; Lucas, K.E.; Vaca, D.A. Comparison of the PLL Control techniques applied in Photovoltaic System. In Proceedings of the 2019 IEEE 15th Brazilian Power Electronics Conference and 5th IEEE Southern Power Electronics Conference (COBEP/SPEC), Santos, Brazil, 1-4 December 2019; pp. 1-6.

42. Li, S.; Xiao, Y.; Liang, J.N.; Meng, L. Research on phase-locked loop of photo voltaic grid-connected inverter in weak grid. In Proceedings of the 2019 14th IEEE Conference on Industrial Electronics and Applications (ICIEA), Xi'an, China, 19-21 June 2019; pp. 1476-1479.

43. Pan, H.; Li, Z.; Wei, T. A Novel Phase-Locked Loop with Improved-Dual Adaptive Notch Filter and Multi-Variable Filter. IEEE Access 2019, 7, 176578-176586. [CrossRef]

44. Sadeque, F.; Benzaquen, J.; Adib, A.; Mirafzal, B. Direct Phase-Angle Detection for Three-Phase Inverters in Asymmetrical Power Grids. IEEE J. Emerg. Sel. Top. Power Electron. 2020, 1. [CrossRef]

45. Pérez-Estévez, D.; Doval-Gandoy, J. Grid-Tied Inverter with AC Voltage Sensorless Synchronization and Soft Start. IEEE Trans. Ind. Appl. 2019, 55, 4920-4933. [CrossRef]

46. Batool, Z.; Biricik, S.; Komurcugil, H.; Ngo, T.; Vu, T.V. Photovoltaic Supplied T-Type Three- Phase Inverter with Harmonic Current Compensation Capability. In Proceedings of the 2019 2nd International Conference on Smart Grid and Renewable Energy (SGRE), Singapore, 25-28 November 2019; pp. 1-5.

47. El Kadi, Y.A.; Lakhal, Y.; Baghli, F.Z. Compensation of the harmonic pollution by photovoltaic systems under variable solar radiation. In Proceedings of the 2019 International Conference of Computer Science and Renewable Energies (ICCSRE), Agadir, Morocco, 22-24 July 2019; pp. 1-4.

48. Zhao, T.; Zhang, X.; Mao, W.; Wang, M.; Wang, F.; Wang, X.; Xu, J. Harmonic Compensation Strategy for Extending the Operating Range of Cascaded H-Bridge PV Inverter. IEEE J. Emerg. Sel. Top. Power Electron. 2020, 8, 1341-1350. [CrossRef]

49. Wang, M.; Zhang, X.; Zhao, T.; Ma, M.; Hu, Y.; Wang, F.; Wang, X. Harmonic Compensation Strategy for Single-Phase Cascaded H-Bridge PV Inverter under Unbalanced Power Conditions. IEEE Trans. Ind. Electron. 2020, 67, 10474-10484. [CrossRef]

50. De Oliveira, A.L.P.; Xavier, L.S.; Callegari, J.M.S.; Cupertino, A.F.; Mendes, V.F.; Pereira, H.A. Partial Harmonic Current Compensation Applied to Multiple Photovoltaic Inverters in a Radial Distribution Line. In Proceedings of the 2019 IEEE 15th Brazilian Power Electronics Conference and 5th IEEE Southern Power Electronics Conference (COBEP/SPEC), Santos, Brazil , 1-4 December 2019; pp. 1-6.

51. Chen, H.; Liu, H.; Xing, Y.; Hu, H.; Sun, K. Analysis and design of enhanced DFT-based controller for selective harmonic compensation in active power filters. In Proceedings of the 2018 IEEE Applied Power Electronics Conference and Exposition (APEC), Charlotte, NC, USA, 4-8 March 2018; pp. 1305-1309.

52. Rajeev, M.; Divya, S. Harmonic Compensation by Transformer-less Grid-tied PV inverter using Conservative Power Theory. In Proceedings of the 2019 IEEE 5th International Conference for Convergence in Technology (I2CT), Bombay, India, 29-31 March 2019; pp. 1-5.

53. Shawky, A.; Sayed, M.A.; Takeshita, T. Selective Harmonic Compensation of Three Phase Grid tied SEPIC based Differential inverter. In Proceedings of the 2019 IEEE Applied Power Electronics Conference and Exposition (APEC), Anaheim, CA, USA, 17-21 March 2019; pp. 396-403. 
54. Xavier, L.S.; Cupertino, A.F.; Pereira, H.A.; Mendes, V.F. Partial Harmonic Current Compensation for Multifunctional Photovoltaic Inverters. IEEE Trans. Power Electron. 2019, 34, 11868-11879. [CrossRef]

55. Agrawal, S.; Vaishnav, S.K.; Ajit.; Somani, R.K. Active Power Filter for Harmonic Mitigation of Power Quality Issues in Grid Integrated Photovoltaic Generation System. In Proceedings of the 2020 7th International Conference on Signal Processing and Integrated Networks (SPIN), Noida, India, 27-28 February 2020; pp. 317-321.

56. Smadi, A.A.; Lei, H.; Johnson, B.K. Distribution System Harmonic Mitigation using a PV System with Hybrid Active Filter Features. In Proceedings of the 2019 North American Power Symposium (NAPS), Wichita, Kansas, 13-15 October 2019; pp. 1-6.

57. Baghaee, H.R.; Mlakić, D.; Nikolovski, S.; Dragicčvić, T. Anti-Islanding Protection of PV-Based Microgrids Consisting of PHEVs Using SVMs. IEEE Trans. Smart Grid 2020, 11, 483-500. [CrossRef]

58. Zhang, X.; Gamage, D.; Rashid, Y.; Manglani, V.; Ukil, A. PQ Control-based Novel Passive Islanding Detection Method for Renewable Energy Application. In Proceedings of the 2019 International Conference on Electronics, Information, and Communication (ICEIC), Auckland, New Zealand, 22-25 January 2019; pp. 1-4.

59. Mlakić, D.; Baghaee, H.R.; Nikolovski, S. A Novel ANFIS-Based Islanding Detection for Inverter-Interfaced Microgrids. IEEE Trans. Smart Grid 2019, 10, 4411-4424. [CrossRef]

60. Park, S.; Kwon, M.; Choi, S. Reactive Power P O Anti-Islanding Method for a Grid-Connected Inverter with Critical Load. IEEE Trans. Power Electron. 2019, 34, 204-212. [CrossRef]

61. Voglitsis, D.; Papanikolaou, N.P.; Kyritsis, A.C. Active Cross-Correlation Anti-Islanding Scheme for PV Module-Integrated Converters in the Prospect of High Penetration Levels and Weak Grid Conditions. IEEE Trans. Power Electron. 2019, 34, 2258-2274. [CrossRef]

62. Pal, D.; Panigrahi, B.K.; Kewat, S. A Hybrid Method for Islanding Detection of Inverter Interfaced Distributed Generators Utilizing Superimposed Component of d-axis Voltage. In Proceedings of the 2019 IEEE Energy Conversion Congress and Exposition (ECCE), Baltimore, MD, USA, 29 September-3 October 2019; pp. $1020-1025$.

63. Resende, Ê.C.; Carvalho, H.T.M.; Melo, F.C.; Coelho, E.A.A.; de Lima, G.B.; de Freitas, L.C.G. A Performance Analysis of Active Anti-Islanding Methods Based on Frequency Drift. In Proceedings of the 2019 IEEE 15th Brazilian Power Electronics Conference and 5th IEEE Southern Power Electronics Conference (COBEP/SPEC), Santos, Brazil, 1-4 December 2019; pp. 1-6.

64. Mlakić, D.; Baghaee, H.R.; Nikolovski, S. Gibbs Phenomenon-Based Hybrid Islanding Detection Strategy for VSC-Based Microgrids Using Frequency Shift, $T H D_{U}$, and $R M S_{U}$. IEEE Trans. Smart Grid 2019, 10, 5479-5491. [CrossRef]

65. Silwal, S.; Karimi-Ghartemani, M. On transient responses of a class of PV inverters. IEEE Trans. Sustain. Energy 2018, 10, 311-314. [CrossRef]

66. Xu, H.; Su, J.; Liu, N.; Shi, Y. A grid-supporting photovoltaic system implemented by a VSG with energy storage. Energies 2018, 11, 3152. [CrossRef]

67. Yang, L.; Hu, Z. Implementation of Dynamic Virtual Inertia Control of Supercapacitors for Multi-Area PV-Based Microgrid Clusters. Sustainability 2020, 12, 3299. [CrossRef]

68. Hosseinipour, A.; Hojabri, H. Virtual inertia control of PV systems for dynamic performance and damping enhancement of DC microgrids with constant power loads. IET Renew. Power Gener. 2017, 12, 430-438. [CrossRef]

69. Yap, K.Y.; Sarimuthu, C.R.; Lim, J.M.Y. Grid Integration of Solar Photovoltaic System Using Machine Learning-Based Virtual Inertia Synthetization in Synchronverter. IEEE Access 2020, 8, 49961-49976. [CrossRef]

70. Zarina, P.; Mishra, S.; Sekhar, P. Exploring frequency control capability of a PV system in a hybrid PV-rotating machine-without storage system. Int. J. Electr. Power Energy Syst. 2014, 60, 258-267. [CrossRef]

71. Hernández, J.; Sanchez-Sutil, F.; Muñoz-Rodríguez, F.; Baier, C. Optimal sizing and management strategy for PV household-prosumers with self-consumption/sufficiency enhancement and provision of frequency containment reserve. Appl. Energy 2020, 277, 115529. [CrossRef]

72. Karimi, M.; Mokhlis, H.; Naidu, K.; Uddin, S.; Bakar, A. Photovoltaic penetration issues and impacts in distribution network-A review. Renew. Sustain. Energy Rev. 2016, 53, 594-605. [CrossRef] 
73. Vargas, M.C.; Altoé Mendes, M.; Tonini, L.G.R.; Elias Batista, O. Grid Support of Small-scale PV Generators with Reactive Power Injection in Distribution Systems. In Proceedings of the 2019 IEEE PES Innovative Smart Grid Technologies Conference-Latin America (ISGT Latin America), Gramado, Brazil, 15-18 September 2019; pp. 1-6.

74. Shamseh, M.B.; Inzunza, R.; Fukasawa, I.; Tanaka, T.; Ambo, T. Grid Support During Asymmetrical Faults using Negative Sequence Current Injection. In Proceedings of the 2019 IEEE 4th International Future Energy Electronics Conference (IFEEC), Singapore, 25-28 November 2019; pp. 1-6.

75. Shuvra, M.A.; Chowdhury, B. Distributed dynamic grid support using smart PV inverters during unbalanced grid faults. IET Renew. Power Gener. 2019, 13, 598-608. [CrossRef]

76. Islam, M.; Mithulananthan, N.; Hossain, M.J.; Bhumkittipich, K. A New Grid-support Strategy with PV Units to Enhance Short-term Voltage Stability. In Proceedings of the 2019 IEEE PES GTD Grand International Conference and Exposition Asia (GTD Asia), Bangkok, Thailand, 20-23 March 2019; pp. 142-147.

77. Islam, M.; Nadarajah, M.; Hossain, M.J. A Grid-Support Strategy with PV Units to Boost Short-Term Voltage Stability Under Asymmetrical Faults. IEEE Trans. Power Syst. 2020, 35, 1120-1131. [CrossRef]

78. Kuncoro, M.; Darussalam, R.; Sukmono, C.B.; Garniwa, I. Dynamic Power Injection for Solar PV Constant Power Generation. In Proceedings of the 2019 6th International Conference on Information Technology, Computer and Electrical Engineering (ICITACEE), Semarang, Indonesia, 24-25 September 2019; pp. 1-5.

79. Cabrera-Tobar, A.; Zanatta, N.; Aragüés-Peñalba, M.; Salles, M.; Pozo, M.; Bellmunt, O.G. Active power control of a PV generator for large scale photovoltaic power plant without energy storage. In Proceedings of the 2019 IEEE PES Innovative Smart Grid Technologies Conference-Latin America (ISGT Latin America), Gramado, Brazil, 15-18 September 2019; pp. 1-6. [CrossRef]

80. Zhu, Y.; Wen, H.; Chu, G.; Li, X. An Adaptive Constant Power Generation Control Scheme with Simple MPP Estimation for Photovoltaic Systems. In Proceedings of the 2019 10th International Conference on Power Electronics and ECCE Asia (ICPE 2019_ECCE Asia), Busan, Korea, 27-31 May 2019; pp. 1-6.

81. Li, Y.; Wu, J. Optimum Integration of Solar Energy with Battery Energy Storage Systems. IEEE Trans. Eng. Manag. 2020, 1-11. [CrossRef]

82. Ranamuka, D.; Muttaqi, K.M.; Sutanto, D. Flexible AC Power Flow Control in Distribution Systems by Coordinated Control of Distributed Solar-PV and Battery Energy Storage Units. IEEE Trans. Sustain. Energy 2020, 11, 2054-2062. [CrossRef]

83. Samara, S.; Natsheh, E. Intelligent Real-Time Photovoltaic Panel Monitoring System Using Artificial Neural Networks. IEEE Access 2019, 7, 50287-50299. [CrossRef]

84. Garaj, M.; Hong, K.Y.; Shu-Hung Chung, H.; Zhou, J.; Lo, A.W. Photovoltaic Panel Health Diagnostic System for Solar Power Plants. In Proceedings of the 2019 IEEE Applied Power Electronics Conference and Exposition (APEC), Anaheim, CA, USA, 17-21 March 2019; pp. 1078-1083.

85. Haba, C. Monitoring Solar Panels using Machine Learning Techniques. In Proceedings of the 2019 8th International Conference on Modern Power Systems (MPS), Cluj-Napoca, Romania, 21-23 May 2019; pp. 1-6.

86. Massaoudi, M.; Chihi, I.; Sidhom, L.; Trabelsi, M.; Refaat, S.S.; Oueslati, F.S. Performance Evaluation of Deep Recurrent Neural Networks Architectures: Application to PV Power Forecasting. In Proceedings of the 2019 2nd International Conference on Smart Grid and Renewable Energy (SGRE), Singapore, 25-28 November 2019; pp. $1-6$.

87. Vrettos, E.; Gehbauer, C. A Hybrid Approach for Short-Term PV Power Forecasting in Predictive Control Applications. In Proceedings of the 2019 IEEE Milan PowerTech, Milano, Italy, 23-27 June 2019; pp. 1-6.

88. Visser, L.; AlSkaif, T.; van Sark, W. Benchmark analysis of day-ahead solar power forecasting techniques using weather predictions. In Proceedings of the 2019 IEEE 46th Photovoltaic Specialists Conference (PVSC), Chicago, IL, USA, 16-21 June 2019; pp. 2111-2116.

89. Ueshima, M.; Babasaki, T.; Yuasa, K.; Omura, I. Examination of Correction Method of Long-term Solar Radiation Forecasts of Numerical Weather Prediction. In Proceedings of the 2019 8th International Conference on Renewable Energy Research and Applications (ICRERA), Brasov, Romania, 3-6 November 2019; pp. 113-117. 
90. Zhang, R.; Ma, H.; Hua, W.; Saha, T.K.; Zhou, X. Data-Driven Photovoltaic Generation Forecasting Based on a Bayesian Network with Spatial-Temporal Correlation Analysis. IEEE Trans. Ind. Inf. 2020, 16, 1635-1644. [CrossRef]

91. Wang, J.; Zhong, H.; Lai, X.; Xia, Q.; Wang, Y.; Kang, C. Exploring Key Weather Factors From Analytical Modeling Toward Improved Solar Power Forecasting. IEEE Trans. Smart Grid 2019, 10, 1417-1427. [CrossRef]

92. Atencio Espejo, F.E.; Grillo, S.; Luini, L. Photovoltaic Power Production Estimation Based on Numerical Weather Predictions. In Proceedings of the 2019 IEEE Milan PowerTech, Milano, Italy, 23-27 June 2019; pp. 1-6

93. Huang, W.; Zhang, C.; Zhang, X.; Meng, J.; Liu, X.; Yuan, B. Photovoltaic Power Prediction Model Based on Weather Forecast. In Proceedings of the 2019 IEEE Sustainable Power and Energy Conference (iSPEC), Brasov, Romania, 20-24 November 2019; pp. 1596-1600.

94. Nikolovski, S.; Reza Baghaee, H.; Mlakić, D. ANFIS-Based Peak Power Shaving/Curtailment in Microgrids Including PV Units and BESSs. Energies 2018, 11, 2953. [CrossRef]

95. Eltawil, M.A.; Zhao, Z. Grid-connected photovoltaic power systems: Technical and potential problems-A review. Renew. Sustain. Energy Rev. 2010, 14, 112-129. [CrossRef]

96. Haque, M.M.; Wolfs, P. A review of high PV penetrations in LV distribution networks: Present status, impacts and mitigation measures. Renew. Sustain. Energy Rev. 2016, 62, 1195-1208. [CrossRef]

97. Yazdani, S.; Ferdowsi, M.; Davari, M.; Shamsi, P. Advanced current-limiting and power-sharing control in a PV-based grid-forming inverter under unbalanced grid conditions. IEEE J. Emerg. Sel. Top. Power Electron. 2019, 8, 1084-1096. [CrossRef]

98. Tafti, H.D.; Konstantinou, G.; Townsend, C.D.; Farivar, G.G.; Sangwongwanich, A.; Yang, Y.; Pou, J.; Blaabjerg, F. A Comparative Study of Flexible Power Point Tracking Algorithms in Photovoltaic Systems. In Proceedings of the 2019 IEEE 4th International Future Energy Electronics Conference (IFEEC), Singapore, 25-28 November 2019; pp. 1-6.

99. Ejgar, M.; Momin, B. Solar plant monitoring system: A review. In Proceedings of the 2017 International Conference on Computing Methodologies and Communication (ICCMC), Erode, India, 18-19 July 2017; pp. 1142-1144.

100. Seme, S.; Štumberger, B.; Hadžiselimović, M.; Sredenšek, K. Solar Photovoltaic Tracking Systems for Electricity Generation: A Review. Energies 2020, 13, 4224. [CrossRef]

101. Ali, A.; Almutairi, K.; Malik, M.Z.; Irshad, K.; Tirth, V.; Algarni, S.; Zahir, M.; Islam, S.; Shafiullah, M.; Shukla, N.K. Review of online and soft computing maximum power point tracking techniques under non-uniform solar irradiation conditions. Energies 2020, 13, 3256. [CrossRef]

102. Mohamed Hariri, M.H.; Mat Desa, M.K.; Masri, S.; Mohd Zainuri, M.A.A. Grid-Connected PV Generation System-Components and Challenges: A Review. Energies 2020, 13, 4279. [CrossRef]

103. Kavya Santhoshi, B.; Mohana Sundaram, K.; Padmanaban, S.; Holm-Nielsen, J.B.; KK, P. Critical review of PV grid-tied inverters. Energies 2019, 12, 1921. [CrossRef]

104. Meegahapola, L.; Sguarezi, A.; Bryant, J.S.; Gu, M.; Conde D, E.R.; Cunha, R. Power System Stability with Power-Electronic Converter Interfaced Renewable Power Generation: Present Issues and Future Trends. Energies 2020, 13, 3441. [CrossRef]

105. Ezhiljenekkha, G.; MarsalineBeno, M. Review of Power Quality Issues in Solar and Wind Energy. Mater. Today Proc. 2020, 24, 2137-2143. [CrossRef]

106. Li, W.; Ren, H.; Chen, P.; Wang, Y.; Qi, H. Key Operational Issues on the Integration of Large-Scale Solar Power Generation-A Literature Review. Energies 2020, 13, 5951. [CrossRef]

107. Hossain, E.; Faruque, H.M.R.; Sunny, M.; Haque, S.; Mohammad, N.; Nawar, N. A Comprehensive Review on Energy Storage Systems: Types, Comparison, Current Scenario, Applications, Barriers, and Potential Solutions, Policies, and Future Prospects. Energies 2020, 13, 3651. [CrossRef]

108. Bosman, L.B.; Leon-Salas, W.D.; Hutzel, W.; Soto, E.A. PV System Predictive Maintenance: Challenges, Current Approaches, and Opportunities. Energies 2020, 13, 1398. [CrossRef]

109. Berrizbeitia, S.E.; Jadraque Gago, E.; Muneer, T. Empirical Models for the Estimation of Solar Sky-Diffuse Radiation. A Review and Experimental Analysis. Energies 2020, 13, 701. [CrossRef] 
110. Mosavi, A.; Salimi, M.; Faizollahzadeh Ardabili, S.; Rabczuk, T.; Shamshirband, S.; Varkonyi-Koczy, A.R. State of the art of machine learning models in energy systems, a systematic review. Energies 2019, 12, 1301. [CrossRef]

Publisher's Note: MDPI stays neutral with regard to jurisdictional claims in published maps and institutional affiliations.

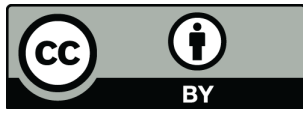

(C) 2020 by the authors. Licensee MDPI, Basel, Switzerland. This article is an open access article distributed under the terms and conditions of the Creative Commons Attribution (CC BY) license (http:/ / creativecommons.org/licenses/by/4.0/). 